\title{
MONITORING AND PROTECTION OF FOREST ECOLOGICAL TOURISM RESOURCES BY DYNAMIC MONITORING SYSTEM
}

\author{
MONITOROWANIE I OCHRONA LEŚNYCH ZASOBÓW TURYSTYKI \\ EKOLOGICZNEJ PRZEZ DYNAMICZNY SYSTEM MONITORINGU
}

\begin{abstract}
Forest can adjust climate and provide resources for the development of the society and tourism as well as promote the progress of human civilization, which is of great significance to the survival and development of human beings. With the industrial development and the improvement of people's living standard, the development strength on forest resources is becoming higher than ever before. As forest resources are important resources which can maintain the ecological balance of the earth, its monitoring and protection is necessary. Hence, remote sensing technology has been developed for monitoring the changes of forest resources, which has the quickness characteristics and real-time spatial information acquisition and analysis capacities. This paper firstly introduced the geographical location, geomorphology, climate status, soil and vegetation types of Zhangjiakou City, Hebei Province and the basic theory of remote sensing monitoring such as vegetation spectral reflectance and normalized differential vegetation index $(N D V I)$. Then, the $N D V I$ was used to analyse the vegetation coverage and area ratio of Zhangjiakou City in 2006, 2010 and 2016. It was found that the vegetation coverage during the ten years from 2006 to 2016 showed an overall trend of growth. Conclusions: It is concluded that dynamic monitoring can effectively monitor and protect forest vegetation, which provided ideas for the follow-up forestry planning and ecological tourism development in Zhangjiakou.
\end{abstract}

Keywords: dynamic monitoring system, environment information collection, information resource monitoring, forest ecological tourism

\section{Introduction}

As the environment we live and important resources for social development, forest can maintain the ecological balance of the earth [1]. The ecological resources of the forest not only provide the necessary timber and forest byproducts for urban construction [2], but also store water, release oxygen and regulate the climate [3] so that the urban heat island effect can be alleviated. The management of forest resources has been transformed from the pursuit of simple economic benefits to the pursuit of economic, humanistic and ecological benefits. Forest is also of great value to tourism. Forest ecological tourism based on forest resources are widely favored by tourists. However, with the development of forest ecological tourism, there are some environmental problems for the exploitation of forest

\footnotetext{
${ }^{1}$ College of Tourism and Service Management, Nankai University, No. 38, Tongyan Road, Haihe Education Park, Jinnan district, Tianjin 300350, China, email: ibm_andy@126.com
} 
ecological resources. Therefore, it is very important to protect forest resources. As the remote sensing technology has the ability to obtain and analyse spatial information rapidly and instantaneously, it has been more and more frequently applied to the dynamic monitoring of forest ecological environment [4]. In recent years, there have been increasing researches on forest dynamic monitoring with the remote sensing technology. Ranjan et al. [5] evaluated LU/LC (land use/land cover) changes in the forest coverage area of Dalmatian Wildlife Reserve in India based on remote sensing, GPS and GIS technologies. Using high-resolution satellite data, they studied the changes in forest cover in 2009, 2011, 2013, 2015 and 2016 and found that the conversion of forest cover to farmland/bare land was growing faster and faster due to the transfer of farming, forest fires and deforestation and the farmers' colonization and encroachment in forest areas was accelerated. Zhang et al. [6] provided a data processing method for hyperspectral remote sensing image analysis and conducted an investigation, monitoring and assessment of urban forest in natural disaster areas based on hyperspectral remote sensing technology. They evaluated and analysed hyperspectral remote sensing images combining with examples of forest fires in California, Masson pine caterpillar pest disaster in the urban forest of Greater Hinggan Mountains and conifer species in California. It was proved that hyperspectral remote sensing was effective in forest fire monitoring, pest monitoring and investigation of changes in urban forest resources in natural disaster areas. Deng et al. [7] measured forest resources at a single tree level by using high-resolution images combined with GPS, RS and GIS techniques and extracted the tree tops of three groups of trees using a $3 \times 3$ pixel moving window filter and the tree crown (ITC) method and annotated all the tree tops with the species attributes on the map. This paper analysed the application of remote sensing technology in the dynamic monitoring of forest ecological resources and investigated the changes of forest ecological resources in Zhangjiakou, Hebei, China through dynamic monitoring system, providing guidance for the implementation of ecological protection strategy of government. To analyse the forest ecological resources based on remote sensing images, this study calculated vegetation coverage by combining normalized differential vegetation index $(N D V I)$ with dimidiate pixel model. It was found that remote sensing images could effectively reflect the changes of vegetation coverage of a region in some period and had an important role in the monitoring of forest environment, indicating that remote sensing technology was reliable in the monitoring of forest ecological resources.

\section{Materials and methods}

\section{Overview of forest ecological resources}

The forest ecological environment system is the most extensive and the most complex and important natural ecosystem in the terrestrial ecosphere [8]. The forest has the richest diversity of species and biological resources in all the ecosystems in the world. The forest ecological system has long existed and reaches the current balanced state with each link coordinated through a long evolutionary process. Although the forest area accounts for only about one third of the land area, the annual growth amount of forest plants accounts for more than half of the annual growth amount of land plants. In addition, a wide range of flora and fauna exist in the forest, including $90 \%$ of terrestrial plants. The number and type of animals in the forest is also much higher than other ecosystems [9]. In addition to plants, there are abundant biological species in the forest area, including mammals, arthropod 
animals, link animals, protozo, fungi, bacteria, algae, etc. The coverage of forest vegetation is beneficial to wind prevention, sand fixation and water and soil conservation [10].

The forest ecosystem and climate are mutually reinforcing, and the changes of both will have an impact on each other [11]. Forest ecological system has an extremely high stability; however, with the constant growth of population and development of economy, more and more human activities has resulted in the overuse of forest resources, which brings severe threatens to the forest ecological system [12].

Forest ecological resources not only have high economic value, but also have high tourism value. With the development and construction of forest ecological resources, forest ecological tourism are developing continuously. However, due to the lack of sufficient awareness of sustainable development, forest resources have been greatly damaged. Through the daily life and production, people gradually realized the value of forest resources. By monitoring the changes of the forest ecological environment, we can evaluate and improve the forest ecological environment more scientifically, so as to ensure the sustainable development of resources [13].

\section{Geological environment and vegetation distribution of Zhangjiakou}

Zhangjiakou City is a prefecture-level city under the jurisdiction of Hebei Province and is located in the northwest of Hebei Province. As an important central city in northwestern Hebei Province, Zhangjiakou is a transportation hub connecting Beijing, Tianjin and Jin-Meng areas. It is located at longitude $113^{\circ} 50^{\prime}$ to $116^{\circ} 30^{\prime}$ and latitude $39^{\circ} 30^{\prime} \sim 2^{\circ} 10^{\prime}$ (Fig. 1).

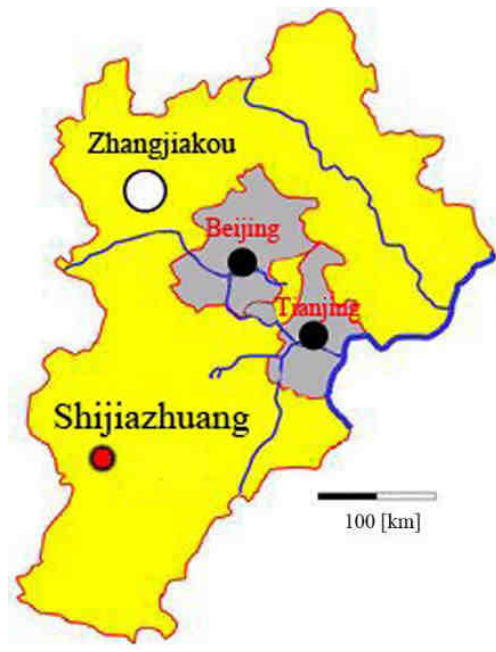

Fig. 1. Geographical location of Zhangjiakou

The topography of Zhangjiakou is high in the northwest and low in the southeast, belonging to two first-class tectonic units of the Inner Mongolia-Daxinganling fold system and the Sino-Korean quasi-platform. The Yinshan mountains go through the city and divide it into two parts - Bashang area and Baxia area, which are with significantly different geomorphic units. The Bashang area is the plateau area while the Baxia area is the low semi 
basin area. The distribution area of magmatic rocks in Zhangjiakou is wide, accounting for a large proportion, with various types of rocks. Zhangjiakou belongs to the temperate continental monsoon climate [14], and its climate change is obvious throughout the year. In spring, the humidity is low and the climate is dry with much winds and sands. In autumn, there are mostly sunny days and the temperature is moderate. Summer lasts short with high temperature, abundant rainfall and humid climate. Winter lasts long with low temperature, less rainfall and dry climate. The Bashang area has moderate annual rainfall amount and few high temperature days and is suitable for the growth of plants. Besides, the area has rich land resources, thus it is good for agriculture and animal husbandry development. Zhangjiakou has a land area of $36564 \mathrm{~km}^{2}$ and a forest coverage rate of $17.29 \%$. The land area for forestry is $20079 \mathrm{~km}^{2}$, of which, the forest land area is $6181 \mathrm{~km}^{2}$, the shrub forest land area is $2131 \mathrm{~km}^{2}$, the unpaved forestry land area is $3649 \mathrm{~km}^{2}$, the non-forest land is $7866 \mathrm{~km}^{2}$, and the live stumpage volume is $2,086,000 \mathrm{~m}^{2}$. The total area of ecological public welfare forest is $4731.8 \mathrm{~km}^{2}$, and the total area of commercial forest is $1449.5 \mathrm{~km}^{2}$, including $718 \mathrm{~km}^{2}$ of timber forest and $731.5 \mathrm{~km}^{2}$ of economic forest. The tree species are mainly pine, larch, arborvitae, aspen, birch, oak, poplar, willow and elm. Young aged forests account for above $61.2 \%$ of the natural forests. As for artificial afforestation, those with above one year old occupy the majority, with a percentage of over $54.5 \%$ of the artificial afforestation. The abundant forest resources have brought great advantages to the development of forest ecological tourism in Zhangjiakou. Therefore, monitoring and protection of forest resources is conducive to the better development of forest ecological tourism.

\section{Remote sensing dynamic monitoring of forest resources}

Spectral signal of vegetation and data selection

Vegetation spectral reflectance characteristics

Accurate estimation of forest biomass is of important values to the protection of forest ecological resources [15], which can be realized by remote sensing technology. Remote sensing technology obtains remote sensing images through acquiring electromagnetic wave information by detecting ground objects with the remote sensor. Due to the different imaging time, the spectrum and geometric features of the ground objects will show differences with evident rules. The band can be divided into three areas: visible light area, near-infrared reflection area and mid-infrared reflection area. As shown in Figure 2, the visible light area is affected by plant pigments, especially chlorophyll, whose wavelength range is $0.4-0.7 \mu \mathrm{m}$. Since chlorophyll has an absorption effect, the spectral curve of a healthy green plant shows a reflection peak at about $0.55 \mu \mathrm{m}$ in the visible light area and two reflection troughs at 0.45 and $0.675 \mu \mathrm{m}$. Affected by the internal structure of the blade, a wide region with relatively high reflectivity occurs in the near-infrared reflection area and a steep slope appears in the range of 0.7 to $0.8 \mu \mathrm{m}$, indicating that the reflectivity increases sharply in this range. Affected by the water content of the green plant, the mid-infrared reflection area has a wavelength range of 1.3 to $2.6 \mu \mathrm{m}$. Two water absorption bands appear at 1.45 and $1.95 \mu \mathrm{m}$ respectively, leading to two reflection valleys and two reflection peaks. It can be seen that the pigment contained in plant leaves (especially chlorophyll), the internal structure of leaves and the moisture content of them determine the spectral reflectance feature differences [16]. 


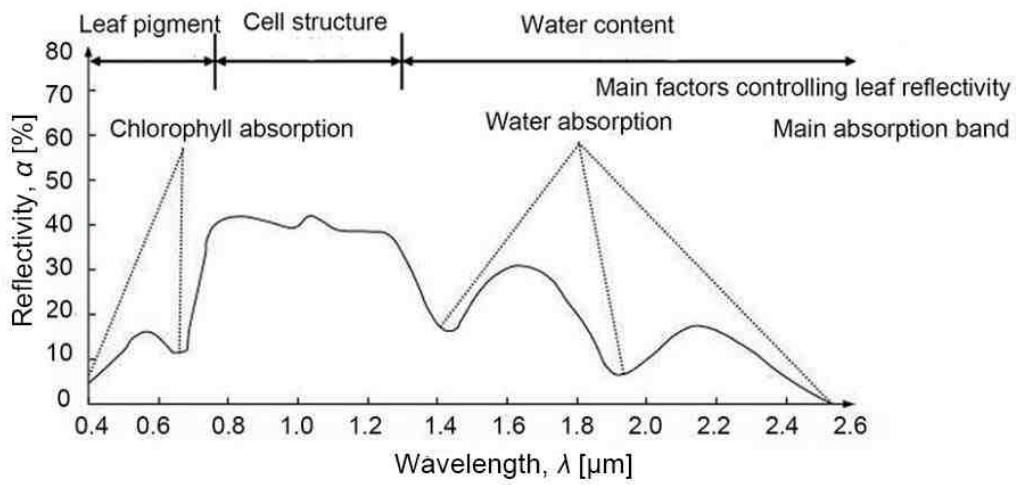

Fig. 2. Vegetation spectral reflectance feature curve

In addition to the above three basic characteristics, plant species, health status and the season in which they are located, as well as the topography, soil and climate all have an impact on the vegetation spectral curve.

Vegetation index selection

Vegetation index refers to the numerical value that is obtained through the combination operation of various wave bands acquired by the remote sensing technology, which can reflect the growth condition of plants in the remote sensing images. Growth state of vegetation is the key of regional ecological environment [17]. Vegetation index calculation generally involves the near-infrared band and the visible infrared band. As plants have a strong reflection characteristic to the near-infrared band and a strong absorption characteristic to the visible infrared band, the combination computation of the two bands can obtain vegetation indexes with differences. The common vegetation indexes are ratio vegetation index, normalized difference vegetation index, difference vegetation index and enhanced vegetation index. In this paper, normalized difference vegetation index was applied for the calculation of vegetation coverage.

\section{Vegetation coverage monitoring model}

NDVI index

NDVI (Normalized Difference Vegetation Index) can separate vegetation from water and soil, which is the best representation of vegetation growth state and coverage and can reflect the changes of ecological environment in a region. Its expression is:

$$
N D V I=\frac{N I R-R}{N I R+R}
$$

where NIR is the reflectivity value in the near infrared band and $R$ is the reflectivity value in the infrared band.

NDVI index can reflect species and growth status of vegetation in unit pixel and detect the number, species and morphology of organisms in the range, which has great value in monitoring ecological resources. NDVI has many advantages and can eliminate most of the 
impact of atmospheric changes on the remote sensing image, and its calculation results are within the range of $[-1,1]$, which can avoid the situation that the computation results are too large or small. The closer the value of $N D V I$ to 1 , the better the growth state of vegetation and the higher the vegetation coverage rate; the closer the value of NDVI to -1 , the poorer the growth state of vegetation and the lower the vegetation coverage rate. NDVI index can help understand the growth condition of vegetation, biodiversity and ecological development level of a region. However, it still has deficiencies. For example, high saturation state can appear in vegetation densely covered areas and atmospheric correction can only reduce the error impact on the remote sensing images within a limited scope.

Dimidiate pixel model

Each pixel in the image is composed of multiple components which have contributions to the pixel information. By decomposing the remote sensing information, i.e., vegetation indexes or wave bands, in the pixels and establishing pixel decomposition models, the vegetation coverage can be calculated, which is called pixel decomposition method. The pixel dichotomy model is one of the linear models. Assuming that each pixel is composed with only ground surface covered with vegetation and ground surface uncovered with vegetation, then the two components form the spectral information of the pixel, their area ratio in the pixel is weight and the ratio of the ground surface covered with vegetation is the vegetation coverage of the pixel.

Then, the following equation can be obtained:

$$
f_{c}=\frac{S-S_{\text {soil }}}{S_{\text {veg }}-S_{\text {soil }}}
$$

where $f_{c}$ refers to the vegetation coverage reflected in the remote sensing information, $S$ refers to all the remote sensing information, $S_{\text {soil }}$ refers to the pixel remote sensing information of soil and $S_{v e g}$ refers to the pixel remote sensing information of all vegetation pixels.

By combing equation (2) with $N D V I$, the following equation can be obtained:

$$
f_{c}=\frac{N D V I-N D V I_{\text {soil }}}{N D V I_{\text {veg }}-N D V I_{\text {soil }}}
$$

where $N D V I_{\text {soil }}$ stands for the $N D V I$ value without vegetation pixel and $N D V I_{\text {veg }}$ stands for the $N D V I$ value of all vegetation pixels.

Equation (3) can be applied to the calculation of vegetation coverage.

\section{Results and discussion}

The forest ecological resources of Zhangjiakou from 2006 to 2016 were monitored by remote sensing technology. Remote sensing image data of Zhangjiakou in 2006, 2010 and 2016 were selected as the research subjects. Changes of vegetation coverage in the past ten years were analysed. In order to facilitate the calculation of vegetation coverage, the remote sensing images were pre-processed by ortho correction, atmospheric correction, image cutting and so on. The NDVI value was calculated by the remote sensing processing software ERDAS IMAGINE. The vegetation coverage of Zhangjiakou in 2006, 2010 and 2016 is shown in Figure 3. 


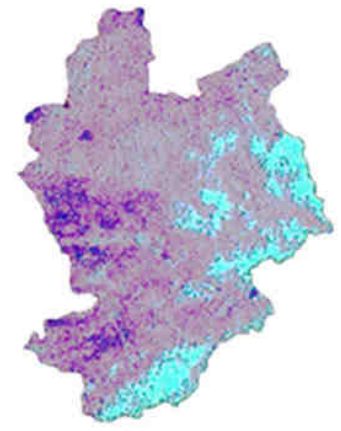

2006

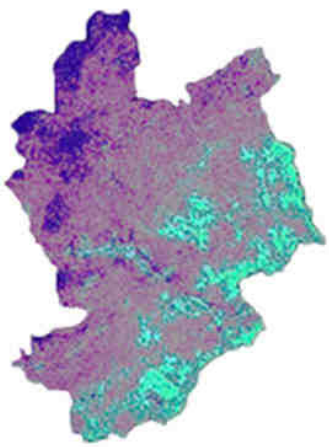

2016

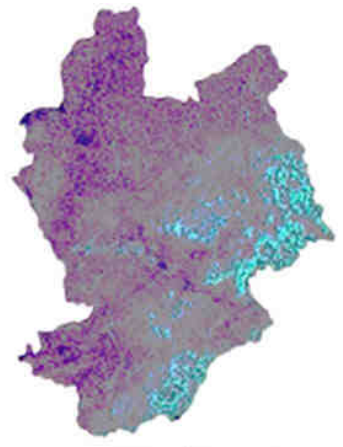

2010

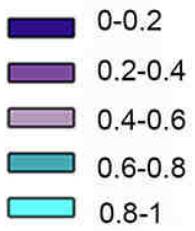

Fig. 3. Vegetation coverage grading of Zhangjiakou in 2006, 2010 and 2016

As shown in Figure 3, the vegetation coverage in Zhangjiakou in the ten years changed significantly. By calculating the coverage ratio of vegetation of different levels, Figure 4 was drawn for a comparison.
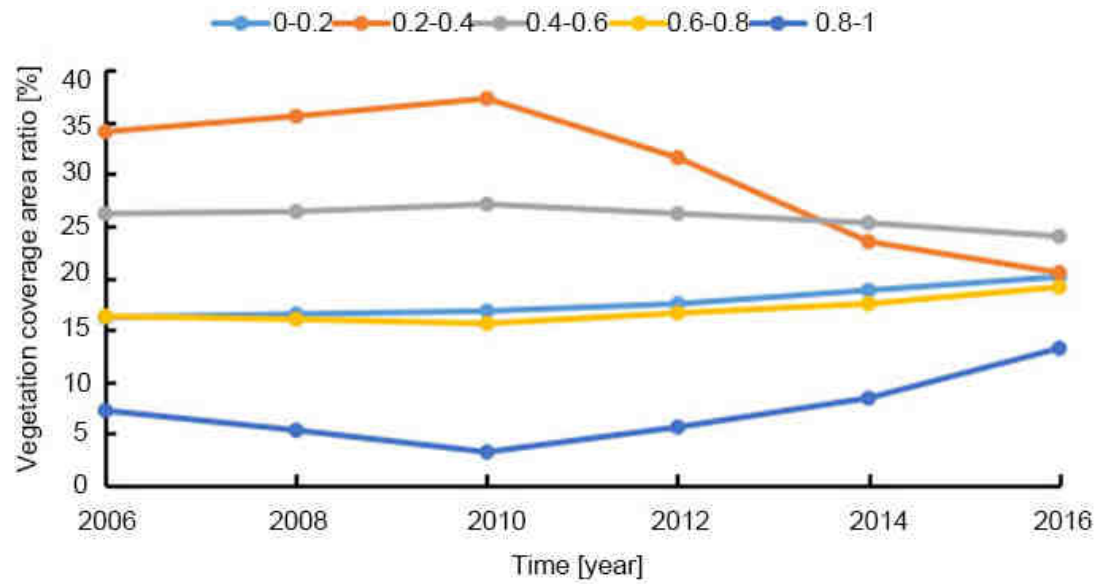

Fig. 4. The vegetation coverage area ratio in Zhangjiakou from 2006 to 2016 
The vegetation coverage area ratio $f_{c}$ of Zhangjiakou in 2006-2016

\begin{tabular}{|c|c|c|c|c|c|c|}
\hline Grade & $\begin{array}{c}\boldsymbol{f}_{\boldsymbol{c}}[\mathbf{\%}] \\
\text { in 2006 }\end{array}$ & $\begin{array}{c}\boldsymbol{f}_{\boldsymbol{c}}[\mathbf{\%}] \\
\text { in 2008 }\end{array}$ & $\begin{array}{c}\boldsymbol{f}_{\boldsymbol{c}}[\mathbf{\%}] \\
\text { in 2010 }\end{array}$ & $\begin{array}{c}\boldsymbol{f}_{\boldsymbol{c}}[\boldsymbol{\%}] \\
\text { In 2012 }\end{array}$ & $\begin{array}{c}\boldsymbol{f}_{\boldsymbol{c}}[\boldsymbol{\%}] \\
\text { In 2014 }\end{array}$ & $\begin{array}{c}f_{c}[\%] \\
\text { in 2016 }\end{array}$ \\
\hline $0-0.2$ & 16.2 & 16.5 & 16.8 & 17.5 & 18.8 & 20.1 \\
\hline $0.2-0.4$ & 34.1 & 35.6 & 37.3 & 31.6 & 23.5 & 20.5 \\
\hline $0.4-0.6$ & 26.2 & 26.4 & 27.1 & 26.2 & 25.3 & 24 \\
\hline $0.6-0.8$ & 16.3 & 16 & 15.6 & 16.6 & 17.5 & 19.1 \\
\hline $0.8-1.0$ & 7.2 & 5.3 & 3.2 & 5.6 & 8.4 & 13.2 \\
\hline
\end{tabular}

As shown in Figure 4 and Table 1, the bare land area kept decreasing while the area of moderate vegetation coverage was basically unchanged in Zhangjiakou area in the ten years. The area of high vegetation coverage decreased to a certain extent from 2006 to 2010 and rapidly increased from 2010 to 2016 . Overall, the vegetation coverage in Zhangjiakou region was showing an increasing state. Based on the principle of pixel dichotomy model, the normalized vegetation index NDVI in Zhangjiakou area each year was extracted. The vegetation coverage of each image can be obtained by processing the probability distribution of NDVI. The change of vegetation coverage from 2006 to 2016 was obtained through comparison. By quantifying the changes in vegetation coverage and expressing them in numerical values, the changes can be observed more intuitively so that the changing trend can be summarized. The data showed that the vegetation coverage in Zhangjiakou area in 2016 increased by $3.9 \%$ at 0.2 level, $2.8 \%$ at $0.6-0.8$ level and $6 \%$ at $0.8-1$ level and decreased by $13.6 \%$ at $0.2-0.4$ level and $2.2 \%$ at $0.4-0.6$ level compared to 2006.

\section{Conclusions}

Though the forest resources occupy a large space with a wide distribution range in China, its per capita forest area accounts for only one-fourth of the world's per capita forest area, with the forest coverage rate far below the world average level of $31 \%$. Therefore, on the whole, the forest resources in our country are scarce. However, forestry ecological resources are an important guarantee for the sustainable development of our country. The burdens on forests caused by the rapid urbanization process and the development of forest ecological tourism are considerable. Only the dynamic management and protection of forest ecological resources can ensure the sustainable development of resources. As the remote sensing technology has the characteristics of wide coverage and instant information acquisition, it can be applied to the dynamic monitoring of forest resource changes, with the advantages of short period, low cost and promptness. This paper realized the dynamic monitoring of forest ecological resources by remote sensing technology and obtained the remote sensing monitoring model of forest vegetation coverage by combining NDVI index with dimidiate pixel model. Taking Zhangjiakou as an example, remote sensing images were obtained and the forest vegetation coverage rate was calculated by using this method to obtain the vegetation coverage map and area scale table. It was found that the vegetation coverage rate in Zhangjiakou showed an increasing trend, which showed that the ecological resources in Zhangjiakou area were well protected and developed in the past ten years. It showed that the monitoring of forest ecological resources by dynamic monitoring system could effectively protect the forest ecological environment in Zhangjiakou, i.e., the method 
was reliable. However, as the NDVI value always had estimation error and lacked the support of the measured data, it is necessary to further combine the calculated results with the measured results to improve the accuracy of the remote sensing dynamic monitoring system.

\section{References}

[1] Lausch A, Borg E, Bumberger J, Dietrich P, Heurich M, Huth A, et al. Understanding forest health with remote sensing, part iii: requirements for a scalable multi-source forest health monitoring network based on data science approaches. Remote Sensing. 2018; 10:1120. DOI: 10.3390/rs10071120.

[2] Wilkesallemann J, Pütz M, Hirschi C, Fischer C. Conflict situations and response strategies in urban forests in Switzerland. Scandinavian J Forest Res. 2015; 30:204-216. DOI: 10.1080/02827581.2014.1002217.

[3] Landry JS, Ramankutty N. Carbon cycling, climate regulation, and disturbances in Canadian forests: Scientific principles for management. Land. 2015; 4:83-118. DOI: 10.3390/land4010083.

[4] $\mathrm{Hu} \mathrm{L}, \mathrm{Li} \mathrm{W}, \mathrm{Xu} \mathrm{B}$. The role of remote sensing on studying mangrove forest extent change. Int $\mathrm{J}$ Remote Sens. 2018:1-23. DOI: 10.1080/01431161.2018.1455239.

[5] Ranjan AK, Anand A, Singh RK, Vallisree S. LU/LC change detection and forest degradation analysis in Dalma Wildlife Sanctuary using 3S technology: A case study in Jamshedpur-India. AIMS Geosci. 2016;2:273-285. DOI: 10.3934/geosci.2016.4.273.

[6] Zhang H, Song HJ, Yu BC. Application of hyper spectral remote sensing for urban forestry monitoring in natural disaster zones. Int Conf Computer Manage. IEEE; 2011:1-4. DOI: 10.1109/CAMAN.2011.5778867.

[7] Deng S, Katoh M, Guan Q, Yin N, Li MY. Interpretation of forest resources at the individual tree level at Purple Mountain, Nanjing City, China, using WorldView-2 Imagery by combining GPS, RS and GIS technologies. Remote Sens. 2013;6:87-110. DOI: 10.1016/j.foreco.2015.03.039.

[8] Miura S, Amacher M, Hofer T, Sanmiguelayanz J, Thackway R. Protective functions and ecosystem services of global forests in the past quarter-century. Forest Ecol Manage. 2015;352:35-46. DOI: 10.1016/j.foreco.2015.03.039.

[9] Pan Y, Birdsey R A, Phillips OL, Jackson RB. The structure, distribution, and biomass of the world's forests. Ann Rev Ecol Evol Syst. 2013;44:593-622. DOI: 10.1146/annurev-ecolsys-110512-135914.

[10] Yang TT, Ala M, Zhang YS, Wu JB, Wang AZ, Guan DX. Characteristics of soil moisture under different vegetation coverage in Horqin Sandy Land, northern China. PLOS ONE 2018;13:e0198805-. DOI: 10.1371/journal.pone.0198805.

[11] Jaworski T, Hilszczański J. The effect of temperature and humidity changes on insects development their impact on forest ecosystems in the expected climate change. Forest Res Papers. 2013;74:345-355.

[12] Zhang Q, Wang GY, Mi F, Zhang XC, Xu LZ, Zhang YF, et al. Evaluation and scenario simulation for forest ecological security in China. J Forest Res. 2018:1-16. https://link.springer.com/article/10.1007/s11676-018-0773-8.

[13] Touré D, Ge J. The response of plant species diversity to the interrelationships between soil and environmental factors in the limestone forests of Southwest China. J Environ Earth Sci. 2014;4(8):105-122. https://iiste.org/Journals/index.php/JEES/article/view/12751.

[14] Kroto HW, Zielińska M, Rajfur M, Wacławek M. The climate change crisis? Chem Didact Ecol Metrol. 2017;21(1-2):11-27. DOI: 10.1515/cdem-2016-0001.

[15] Wang X, Wang S, Dai L. Estimating and mapping forest biomass in northeast China using joint forest resources inventory and remote sensing data. J Forest Res. 2018;29(3):1-15. DOI: 10.1007/s11676-017-0504-6.

[16] Ji R, Zheng L, Deng X, Zhang Y, Li M. Forecasting chlorophyll content and moisture of apple leaves in different tree growth period based on spectral reflectance. Trans Chin Soc Agric Mach. 2014;45:269-275. DOI: 10.6041/j.issn.1000-1298.2014.08.043.

[17] Gu Z, Duan X, Shi Y, Li Y, Pan X. Spatiotemporal variation in vegetation coverage and its response to climatic factors in the Red River Basin, China. Ecol Indic. 2018;93:54-64. DOI: 10.1016/j.ecolind.2018.04.033. 